Check for updates

Cite this: RSC Adv., 2017, 7, 33177

Received 25th April 2017

Accepted 25th June 2017

DOI: $10.1039 / \mathrm{c} 7 \mathrm{ra0} 4661 \mathrm{~h}$

rsc.li/rsc-advances

\title{
Optimization of culturing conditions for isolated Arthrobacter sp. ZXY-2, an effective atrazine- degrading and salt-adaptive bacterium $\dagger$
}

\author{
Xinyue Zhao, ${ }^{\text {ab }}$ Li Wang, ${ }^{a}$ Linna Du, ${ }^{\mathrm{c}}$ Jixian Yang, ${ }^{a}$ Jing Dong ${ }^{a}$ and Fang Ma (D) *a
}

\begin{abstract}
The increasing salinity in aquatic environments has had a negative impact on the biodegradation of atrazine, an extensively used herbicide which has been proven to pollute soil and water ecosystems. In the present study, a novel atrazine-degrading strain ( $Z X Y-2)$ was isolated from industrial wastewater and identified as the Arthrobacter genus with the 16S rRNA gene. Results indicated that the strain showed a high salinity tolerance, and was able to tolerate $\mathrm{NaCl}$ concentrations up to $10 \%(\mathrm{w} / \mathrm{w})$. Plackett-Burman (PB) multifactorial design and response surface methodology (RSM) were then employed to optimize the culturing conditions. Results showed that among the selected fifteen factors, six contributing factors were obtained. Subsequently, by employing the RSM to model and optimize atrazine degradation, a biodegradation efficiency of $12.73 \mathrm{mg} \mathrm{L}^{-1} \mathrm{~h}^{-1}$ was reached under optimal conditions $\left(34.04{ }^{\circ} \mathrm{C}, \mathrm{pH} 9.0\right.$, inoculum size $10 \%(\mathrm{v} / \mathrm{v}), 2.212 \mathrm{~g} \mathrm{~L}^{-1}$ of sucrose, $6 \mathrm{~g} \mathrm{~L}^{-1}$ of $\mathrm{Na}_{2} \mathrm{HPO}_{4} \cdot 12 \mathrm{H}_{2} \mathrm{O}$, and $50 \mathrm{mg} \mathrm{L}^{-1}$ of atrazine). In addition, a statistically quadratic polynomial mathematical model was suggested $\left(R^{2}=0.9873\right)$. In contrast to other atrazine-degrading bacteria, ZXY-2 appears to be adapted to life under high salinity conditions and sustains excellent atrazine degradation performance. Therefore it could potentially be applied in atrazine bioremediation.
\end{abstract}

\section{Introduction}

Atrazine, an environmentally ubiquitous organic herbicide, has been extensively used to control a variety of broadleaf and grass weeds in agriculture and forestry. ${ }^{\mathbf{1 , 2}}$ Atrazine has been reported to be a possible human carcinogen and is a suspected endocrine disrupter. It is commonly detected in soils, surface water, and ground water near where it is used. ${ }^{3,4}$ Moreover, atrazine has been classified as a major toxicological contaminant, causing increasing concern regarding its presence in the environment. It is therefore critical that improved methods to remove atrazine from the environment are found.

The fate of atrazine in contaminated sites largely depends on microbial metabolism. ${ }^{5}$ Bioaugmentation using atrazine degraders could be an attractive and cost-effective method. However, since ground water salinity has been increasing due to climate change in recent years, the increasing salinity has led to a low biodegradability of atrazine. ${ }^{6}$ This necessitates the

${ }^{a}$ State Key Laboratory of Urban Water Resource and Environment, School of Municipal and Environmental Engineering, Harbin Institute of Technology, Harbin 150090, China. E-mail: mafang@hit.edu.cn; Fax: +86-045186283008; Tel: +86-045186283008 ${ }^{b}$ Section of Sanitary Engineering, Department of Water Management, Delft University of Technology, Delft,2628CN, The Netherlands.E-mail: X.Zhao-3@tudelft.nl

${ }^{c}$ Department of Agriculture and Biotechnology, Wenzhou Vocational College of Science and Technology, Wenzhou 325006, China

$\dagger$ Electronic supplementary information (ESI) available. See DOI: 10.1039/c7ra04661h isolation of atrazine-degrading microorganisms with salt adaptation. Various atrazine-degrading strains, belonging to diverse genera, have been reported to metabolize atrazine as a sole source of carbon and energy (e.g., Pseudomonas, Acinetobacter, Rhodococcus, Arthrobacter, Bacillus, and Variovorax ${ }^{\mathbf{2 , 4}, 7-10}$ ). Although these reported strains seem to show varying abilities to degrade atrazine, with the highest degradation efficiency of $19.03 \mathrm{mg} \mathrm{L}^{-1} \mathrm{~h}^{-1}$, no salt-adaptive capacity has been identified. To the best of our knowledge, only Pseudomonas sp. ADP and Ochrobactrum oryzae have been reported to be capable of degrading atrazine under different salinity conditions; they achieved limited atrazine-degrading efficiencies of $1.04 \mathrm{mg} \mathrm{L}^{-1}$ $\mathrm{h}^{-1}$ and $0.04 \mathrm{mg} \mathrm{\textrm {L } ^ { - 1 }} \mathrm{h}^{-1}$, respectively. ${ }^{6,11}$ Therefore, it is essential to isolate an atrazine-degrading strain with dual capacities of removing atrazine effectively and tolerating salinity efficiently.

Numerous studies show that microbial growth and biodegradation efficiency are influenced by the various mediacomponents (e.g., $\mathrm{C}$ sources and $\mathrm{N}$ sources) and growth conditions (e.g., temperature, $\mathrm{pH}$, and shaking speed). ${ }^{4,12,13}$ For example, a low level of nitrate has no effect on atrazine degradation, while high levels of nitrate would inhibit the removal process; ${ }^{14}$ and sucrose promotes atrazine degradation by Arthrobacter sp. strain DAT1, while it inhibits atrazine degradation by Arthrobacter sp. strain HB-5. ${ }^{\mathbf{1 3 , 1 5}}$ Various mediacomponent factors influence the growth of atrazine-degrading strains in different ways. To better understand the 
relationship between a strain and its growth environment, it is necessary to identify which factors are more influential and to adopt an effective methodology to separate these critical factors from all other factors. Additionally, it is likely that the effects of these factors are interrelated rather than independent. Therefore, investigating the combined effect of these factors is significant for understanding atrazine biodegradation. Considering these factors that vary simultaneously, the statistical Plackett-Burman (PB) design and the central composite design (CCD) based on response surface methodology (RSM) are effective methods for optimization of growth conditions for the biodegradation of atrazine. The PB design provides a way to screen for operational parameters that have significant effects on atrazine degradation. ${ }^{\mathbf{1 6}-18}$ RSM is the statistical technique applied to seek the optimal conditions and understand the interactive effects on the atrazine biodegradation process. ${ }^{\mathbf{1 9 , 2 0}}$

In the present study, an atrazine-degrading strain with effective atrazine-degrading abilities and high salinity tolerance was newly isolated. The culturing conditions that had a significant effect on atrazine degradation were then determined using the PB design. Following, CCD was used to identify the optimal culturing conditions for achieving enhanced atrazine removal efficiency. The combined effect of different environmental factors on atrazine degradation was also investigated.

\section{Experimental}

\subsection{Isolation and enrichment}

Industrial wastewater and soil samples were collected from Jilin Pesticide Plant, China. The enrichment medium consisted of mineral salts medium (MSM), $100 \mathrm{mg} \mathrm{L}^{-1}$ atrazine as the sole nitrogen source, and $3 \mathrm{mg} \mathrm{L}{ }^{-1}$ sucrose as the carbon source. It was autoclaved at $121{ }^{\circ} \mathrm{C}$ for 15 minutes. The MSM contained (per liter) $0.9 \mathrm{~g}$ of $\mathrm{KH}_{2} \mathrm{PO}_{4}, 6.5 \mathrm{~g}$ of $\mathrm{Na}_{2} \mathrm{HPO}_{4} \cdot 12 \mathrm{H}_{2} \mathrm{O}, 0.15 \mathrm{~g}$ of $\mathrm{MgSO}_{4} \cdot 7 \mathrm{H}_{2} \mathrm{O}, 0.01 \mathrm{~g}$ of $\mathrm{FeSO}_{4} \cdot 7 \mathrm{H}_{2} \mathrm{O}$ and $2 \mathrm{~mL}$ of trace element solution. The trace element solution contained (per liter) $0.1 \mathrm{~g}$ of $\mathrm{CoCl}_{2} \cdot 6 \mathrm{H}_{2} \mathrm{O}, 0.425 \mathrm{~g}$ of $\mathrm{MnCl}_{2} \cdot 4 \mathrm{H}_{2} \mathrm{O}, 0.05 \mathrm{~g}$ of $\mathrm{ZnCl}_{2}, 0.01 \mathrm{~g}$ of $\mathrm{NiCl}_{2} \cdot 6 \mathrm{H}_{2} \mathrm{O}, 0.015 \mathrm{~g}$ of $\mathrm{CuSO}_{4} \cdot 5 \mathrm{H}_{2} \mathrm{O}, 0.01 \mathrm{~g}$ of $\mathrm{Na}_{2} \mathrm{MoO}_{4}$ $\cdot 2 \mathrm{H}_{2} \mathrm{O}$ and $0.01 \mathrm{~g}$ of $\mathrm{Na}_{2} \mathrm{SeO}_{4} \cdot 2 \mathrm{H}_{2} \mathrm{O}$. The $\mathrm{pH}$ of the medium was adjusted to 7.0 with $1 \mathrm{M} \mathrm{NaOH}$ solution. Enrichments were carried out at $30{ }^{\circ} \mathrm{C}$ and $150 \mathrm{rpm}$ for seven days. The partially enriched biomass was cultivated in fresh medium for another seven days and then repeated for three times. After one month, the enrichment cultures were plated onto agar plates. Colonies forming a clear zone were identified as possible atrazinedegrading isolates. An isolate named ZXY-2 showed high atrazine biodegradation ability and was selected for further study.

\subsection{Cloning and sequencing of 16S rRNA sequence}

Bacterial DNA was extracted from ZXY-2 using a genomic DNA extraction kit (Sangon, China) following the manufacturer's instructions. Polymerase chain reaction (PCR) was used to amplify the 16S rRNA gene from total bacterial DNA. The PCR conditions consisted of an initial denaturation at $94{ }^{\circ} \mathrm{C}$ for 5 min followed by 30 cycles of denaturation at $94{ }^{\circ} \mathrm{C}$ for $1 \mathrm{~min}$, annealing at $55^{\circ} \mathrm{C}$ for $1 \mathrm{~min}$, and extension at $72^{\circ} \mathrm{C}$ for $1.5 \mathrm{~min}$, and a final 5 min extension at $72{ }^{\circ} \mathrm{C}$. PCR products were sequenced by the TaKaRa Biotechnology Company (Dalian, China). The sequence was compared with those available in the NCBI database using the BLAST program.

\subsection{Incubation of Arthrobacter sp. ZXY-2 under different salinities}

$10 \mathrm{~mL}$ of the enrichment cultures after the log phase were inoculated into flasks with $90 \mathrm{~mL}$ sterilized MSM medium. Each flask was supplemented with $100 \mathrm{mg} \mathrm{L}^{-1}$ atrazine and $0-10 \%$ $\mathrm{NaCl}(\mathrm{w} / \mathrm{w})$. Samples were withdrawn each hour for analysis of atrazine concentration and cell growth.

\subsection{Plackett-Burman design for factors screening}

The PB design was introduced as the first optimization step to identify the culture factors that had significant effects on atrazine degradation by strain ZXY-2. The factors tested included temperature, $\mathrm{pH}$, shaking speed, inoculum size, glucose, sucrose, sodium citrate, $\mathrm{KNO}_{3}, \mathrm{NH}_{4} \mathrm{Cl}$, isopropylamine, $\mathrm{KH}_{2} \mathrm{PO}_{4}$, $\mathrm{Na}_{2} \mathrm{HPO}_{4} \cdot 12 \mathrm{H}_{2} \mathrm{O}, \quad \mathrm{FeSO}_{4} \cdot 7 \mathrm{H}_{2} \mathrm{O}, \mathrm{MgSO}_{4} \cdot 7 \mathrm{H}_{2} \mathrm{O}$, and atrazine concentrations. The independent variables were converted to coded values for computational convenience: the upper limit of a factor was coded as +1 , the lower limit as -1 , and the center level as 0 (Table 1). Fifty-four runs were performed according to the experimental layout (Table $\mathrm{S} 1 \dagger$ ). All the runs were carried out in triplicate, and the average atrazine degradation for each run was used as the response. Atrazine degradation percentages were assessed after 8 hours of incubation. Minitab 17.1 (Minitab Inc., State College, PA, USA) was employed for statistical analysis of the PB design. Regression analysis determined the factors that had a significant $(p<0.01)$ effect on atrazine degradation, and these factors were evaluated in further optimization experiments.

\subsection{Response surface method for optimizing the biodegradation ability}

RSM based on CCD was used to further optimize the culturing conditions. In the present work, fifty-four experimental runs with ten replicates at the center point were designed for the selected six of the eight variables found to be significant in the PB design. The specified ranges of the variables were as follows: temperature $30-40{ }^{\circ} \mathrm{C}, \mathrm{pH} 7-9$, inoculum size $5-10 \%(\mathrm{v} / \mathrm{v})$, sucrose 1-3 $\mathrm{g} \mathrm{L}^{-1}, \mathrm{Na}_{2} \mathrm{HPO}_{4} \cdot 12 \mathrm{H}_{2} \mathrm{O} 6-12 \mathrm{~g} \mathrm{~L}^{-1}$ and atrazine concentration $50-100 \mathrm{mg} \mathrm{L}^{-1}$. The analyzed response was the atrazine degradation after 3 hours of incubation. All experiments were performed in triplicate and their response and predicted values were given in Table S2. $\dagger$

The experimental data was further analyzed by assuming a second order polynomial with linear, quadratic and interaction effects as shown in eqn (1):

$$
Y=b_{0}+\sum_{i=1}^{n} b_{i} X_{i}+\sum_{j=1}^{n} b_{j j} X_{j}^{2}+\sum_{i<j}^{n} b_{i j} X_{i} X_{j}
$$

where $Y$ is the response; $X$ is the input variables; $b_{0}$ is the intercept coefficient; $b_{i}$ is the linear coefficient; $b_{j j}$ is the quadratic coefficient; and $b_{i j}$ is the interaction coefficient. 
Table 1 The factorial levels and the regression analysis of the Plackett-Burman design ${ }^{a}$

\begin{tabular}{|c|c|c|c|c|c|c|c|}
\hline No. & Factors & +1 level & $\begin{array}{l}-1 \\
\text { level }\end{array}$ & Center level & Effect & $T$-Value & $p$-Value \\
\hline$X_{1}$ & Temperature $\left({ }^{\circ} \mathrm{C}\right)$ & 40 & 20 & 30 & 13.192 & 7.85 & $<0.0001^{b}$ \\
\hline$X_{3}$ & Shaking speed (rpm) & 200 & 100 & 150 & -4.067 & -2.42 & 0.021 \\
\hline$X_{4}$ & Inoculum size $(\%(\mathrm{v} / \mathrm{v}))$ & 10 & 1 & 5.5 & 37.008 & 22.03 & $<0.0001^{b}$ \\
\hline$X_{5}$ & Glucose $\left(\mathrm{g} \mathrm{L}^{-1}\right)$ & 2 & 0 & 1 & -6.567 & -3.91 & $<0.0001^{b}$ \\
\hline$X_{8}$ & $\mathrm{KNO}_{3}\left(\mathrm{~g} \mathrm{~L}^{-1}\right)$ & 0.5 & 0 & 0.25 & -2.158 & -1.28 & 0.207 \\
\hline$X_{9}$ & $\mathrm{NH}_{4} \mathrm{Cl}\left(\mathrm{g} \mathrm{L}^{-1}\right)$ & 0.5 & 0 & 0.25 & -6.658 & -3.96 & $<0.0001^{b}$ \\
\hline$X_{10}$ & Isopropylamine $\left(\mathrm{mL} \mathrm{L}^{-1}\right)$ & 5 & 0 & 2.5 & -0.758 & -0.45 & 0.654 \\
\hline$X_{11}$ & $\mathrm{KH}_{2} \mathrm{PO}_{4}\left(\mathrm{~g} \mathrm{~L}^{-1}\right)$ & 1.5 & 0.5 & 1 & 4.067 & 2.42 & 0.021 \\
\hline$X_{12}$ & $\mathrm{Na}_{2} \mathrm{HPO}_{4} \cdot 12 \mathrm{H}_{2} \mathrm{O}\left(\mathrm{g} \mathrm{L}^{-1}\right)$ & 12 & 2 & 7 & 20.500 & 12.20 & $<0.0001^{b}$ \\
\hline$X_{13}$ & $\mathrm{FeSO}_{4} \cdot 7 \mathrm{H}_{2} \mathrm{O}\left(\mathrm{g} \mathrm{L}^{-1}\right)$ & 0.02 & 0 & 0.01 & 2.975 & 1.77 & 0.085 \\
\hline
\end{tabular}

${ }^{a}$ Note: $R$-Sq $=96.06 \% ; R$-Sq (adj.) $=94.35 \% .{ }^{b}$ Significant at “ $p$-value” less than 0.01 .

Minitab 17.1 (Minitab Inc., State College, PA, USA) was used to run an analysis of variance (ANOVA), as well as regression and graphical analyses.

\subsection{Analytical methods}

The atrazine was extracted from the growth medium samples with dichloromethane and then filtered using a sterile filter with $0.22 \mu \mathrm{m}$ pore size (Sartorius Stedim, Germany). The analysis was performed by high-performance liquid chromatography (HPLC, Shimadzu, Japan) equipped with a C18 column (length $25 \mathrm{~cm}$, internal diameter $4.6 \mathrm{~mm}$; Varian) and a UV detector at $220 \mathrm{~nm}$ wavelength. The mobile phase consisted of acetonitrile/water (6/ $4, \mathrm{v} / \mathrm{v}$ ) at a flow rate of $1.0 \mathrm{~mL} \mathrm{~min}^{-1}$. Samples were injected with a constant injection volume of $20 \mu \mathrm{L}$. Atrazine concentration was calculated by comparison to a standard curve.

\section{Results and discussion}

\subsection{Isolation and characterization of the atrazine-degrading strain ZXY-2}

After four rounds of enrichment, a total of fourteen pure isolates were obtained. Among these isolates, a strain designated as ZXY-2 was selected as it completely degraded $100 \mathrm{mg}$ $\mathrm{L}^{-1}$ atrazine within $14 \mathrm{~h}\left(7.14 \mathrm{mg} \mathrm{L^{-1 }} \mathrm{h}^{-1}\right)$ and $50 \mathrm{mg} \mathrm{L}^{-1}$ atrazine within $8 \mathrm{~h}\left(6.25 \mathrm{mg} \mathrm{L}{ }^{-1} \mathrm{~h}^{-1}\right)$. The colonies of strain ZXY-2 were yellowish, wet, circular with semitransparent, and smooth surfaces on MSM agar plates. The 16S rRNA sequences exhibited a high sequence similarity with the members of the genus Arthrobacter and had maximum similarity with Arthrobacter TBD185 (99\%). The sequence was deposited in GenBank under accession number KT778822 and strain ZXY-2 was deposited in China General Microbiological Culture Collection Center (CGMCC) with the deposited number CGMCC no. 10937.

\subsection{Degradation and growth of ZXY-2 at different salinities}

Fig. 1a shows the growth of ZXY-2 grown at a series of salinities: $0 \%, 1 \%, 3 \%, 5 \%$, and $10 \%$. The shortest lag phase (less than 1.5 h) was observed at the $\mathrm{NaCl}$ concentration of $0 \%, 1 \%$ and $3 \%$. The lag phase of ZXY-2 was prolonged with increasing salinity. When the $\mathrm{NaCl}$ concentration reached $10 \%$, the lag phase of
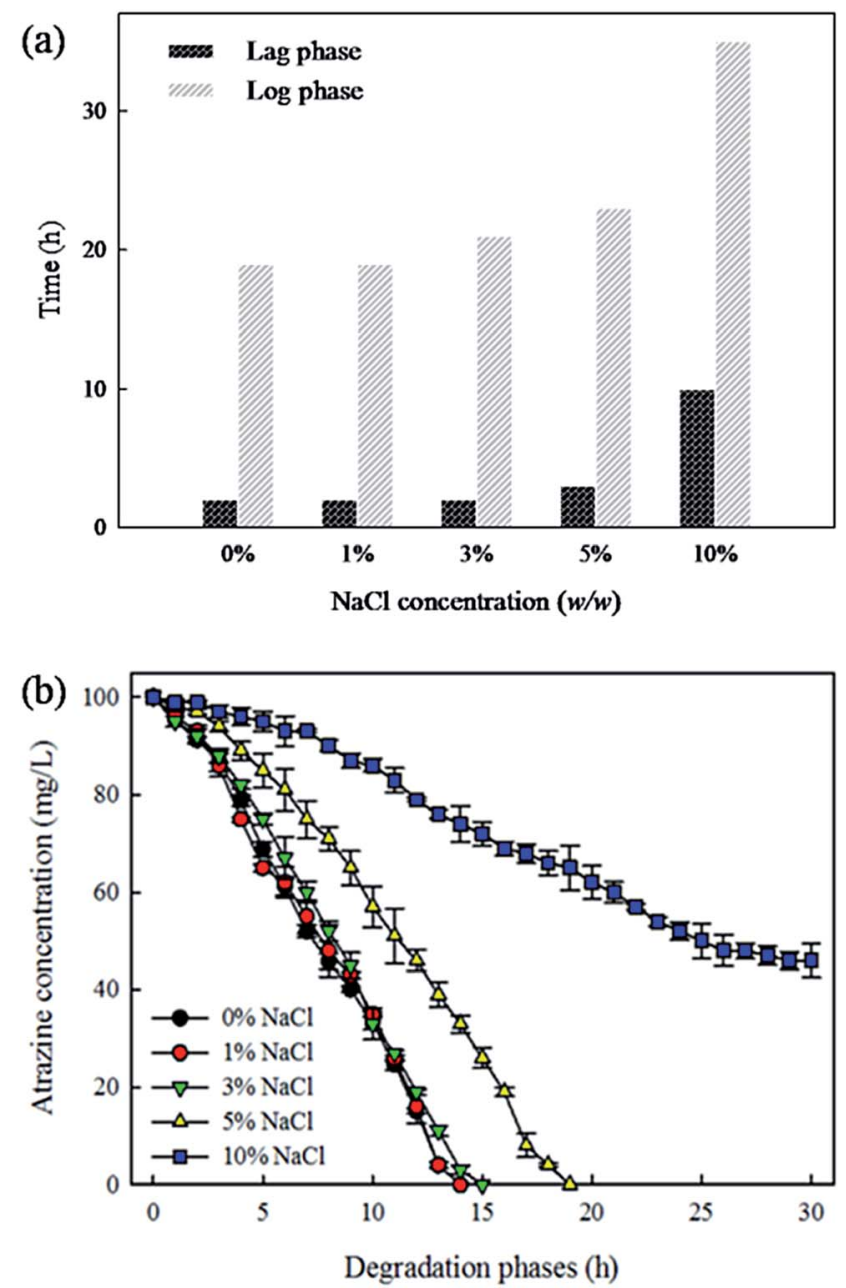

Fig. 1 The growth phase and atrazine degradation of strain ZXY-2 under different salinities. 
strain ZXY-2 lasted for $10 \mathrm{~h}$. As shown in Fig. 1b, more than 99\% of atrazine was degraded with $20 \mathrm{~h}$ when the media were supplemented with $0-5 \% \mathrm{NaCl}$. Even though the concentration of $\mathrm{NaCl}$ reached $10 \%$, strain ZXY-2 could still degrade up to $50 \%$ of atrazine after $30 \mathrm{~h}$. There is limited information about salttolerance atrazine-degrading strains. To date, only Pseudomonas sp. ADP and Ochrobactrum oryzae have been reported to degrade atrazine under salinity conditions, and the two strains could only completely degrade atrazine at $4 \%$ and $1 \%$ salinities with efficiencies of $1.04 \mathrm{mg} \mathrm{L}^{-1} \mathrm{~h}^{-1}$ and $0.04 \mathrm{mg} \mathrm{L}^{-1} \mathrm{~h}^{-1}$, respectively. ${ }^{6,11}$ Therefore, compared with the reported isolates, strain ZXY-2 exhibited higher tolerance toward salts and better degradation efficiency.

\subsection{Plackett-Burman design analysis: critical factors for growth}

Fifteen growth factors including temperature, $\mathrm{pH}$, shaking speed, inoculum size, glucose, sucrose, sodium citrate, $\mathrm{KNO}_{3}$, $\mathrm{NH}_{4} \mathrm{Cl}$, isopropylamine, $\mathrm{KH}_{2} \mathrm{PO}_{4}, \mathrm{Na}_{2} \mathrm{HPO}_{4} \cdot 12 \mathrm{H}_{2} \mathrm{O}, \mathrm{FeSO}_{4}-$ $\cdot 7 \mathrm{H}_{2} \mathrm{O}, \mathrm{MgSO}_{4} \cdot 7 \mathrm{H}_{2} \mathrm{O}$ and atrazine concentrations were used to identify the significant effects on atrazine degradation. The experimental design and the values of atrazine degradation for the fifty-four runs are presented in Tables 1 and S1. $\uparrow$ Degradation percentages of atrazine at different conditions ranged from $5.1 \%$ to $98.3 \%$, indicating that the selected factors had significant effects on atrazine degradation. The regression analysis and $p$-values of the experimental factors are given in Table 1. The high values of $R^{2}(0.9606)$ and adjusted $R^{2}(0.9435)$ indicated that the observed values were in good fit with the modelpredicted values. Additionally, setting a confidence level of $99 \%$ for factor screening, temperature $\left(X_{1}\right), \mathrm{pH}\left(X_{2}\right)$, inoculum size $\left(X_{4}\right)$, glucose $\left(X_{5}\right)$, sucrose $\left(X_{6}\right), \mathrm{NH}_{4} \mathrm{Cl}\left(X_{9}\right), \mathrm{Na}_{2} \mathrm{HPO}_{4} \cdot 12 \mathrm{H}_{2} \mathrm{O}$ $\left(X_{12}\right)$, and atrazine concentration $\left(X_{15}\right)$, were identified as the most influential factors on atrazine degradation.

Previous studies have shown that additional nitrogen or carbon sources have different effects on atrazine degradation. ${ }^{\mathbf{1 2 - 1 4}}$ Among the above significant factors, both glucose (as a carbon source) and $\mathrm{NH}_{4} \mathrm{Cl}$ (as a nitrogen source) had negative coefficients. However, sucrose was found to have a positive coefficient on atrazine degradation (Table 1), suggesting that a relatively high sucrose concentration was needed for atrazine degradation by strain ZXY-2. Sucrose supplementation might promote the growth of strain ZXY-2 and thus enhanced the atrazine degradation. This trend was consistent with previous study that: when atrazine was the sole carbon source for Arthrobacter sp. DAT1, degradation was slow whereas the addition of sucrose as supplemental carbon source resulted in higher degradation rate. ${ }^{13}$

In this study $\mathrm{pH}$ and temperature had significant positive effects within the experimental region with a lower $\mathrm{pH}$ and temperature value resulting in lower atrazine degradation. Higher ones might be beneficial for the bacterial growth, thus resulting in higher atrazine degradation. Previously, many studies had shown that the $\mathrm{pH}$ and temperature are the two important variables concerned and strongly influenced the degradation of toxic pollutants by microorganisms. ${ }^{21-23}$
Additionally, the relatively high $\mathrm{pH}(\mathrm{pH}=9)$ in this study might correspond to the optimal cell growth of the strain, as has been suggested for other strain in previous research. ${ }^{4}$

Among these significant factors $(p<0.01)$, the concentrations of glucose and $\mathrm{NH}_{4} \mathrm{Cl}$ were eliminated due to their negative effect on atrazine degradation. Hence, six factors (temperature, $\mathrm{pH}$, inoculum size, sucrose, $\mathrm{NaHPO}_{4} \cdot 12 \mathrm{H}_{2} \mathrm{O}$ and atrazine concentration) were chosen for further optimization by RSM.

\subsection{Response surface methodology model analysis}

The CCD design was employed for further optimization of atrazine degradation. Based on the results of the PB design, a six-factor CCD with fifty-four experimental runs was carried out (Table $\mathrm{S} 2 \dagger$ ). The observed degradation percentages varied from $21.55 \%$ to $72.25 \%$. The analysis of variance (ANOVA) was used to test the fit of the model (Table 2). The ANOVA of the quadratic regression model demonstrated that the model was highly significant, as was evident from the $F$-test $(F$-value $=$ $69.58)$ with a very low probability value $(p<0.0001)$. The adequacy of the model was indicated by the determination coefficient $\left(R^{2}=0.9873\right)$, which suggested that $98.73 \%$ of the variability in the response could be attributed to the independent variables. The value of the adjusted determination coefficient (adj. $R^{2}=0.9731$ ) was also high, again supporting the significance of the model. The lack of fit test $(p>0.05)$ revealed that the quadratic model was statistically significant and could be used for further analysis.

Effects of the factors with linear, square, and interactive coefficients are shown in Table 2. The $\mathrm{pH}$, inoculum size, sucrose, and atrazine concentrations all showed significant linear effects. The inoculum size and atrazine concentration had higher coefficient values, indicating a higher significant effect on the degradation of atrazine compared with the other factors. Inoculum size showed a positive effect on atrazine degradation, and atrazine concentration had a negative effect. When square terms were considered, only temperature and atrazine concentration were significant.

By applying multiple regression analysis, a predictive quadratic model was fitted with experimental results, and the following regression equation was obtained when only significant terms for atrazine degradation were included (eqn (2)):

$$
\begin{aligned}
Y= & 48.442+2.811 X_{2}+8.255 X_{3}+2.235 X_{4}-9.964 X_{6} \\
& -3.21 X_{1}^{2}+3.94 X_{6}^{2}-1.020 X_{1} X_{3}-1.427 X_{1} X_{4} \\
& +1.137 X_{1} X_{6}-1.307 X_{2} X_{5}-0.781 X_{3} X_{4}-0.829 X_{3} X_{5} \\
& +4.923 X_{3} X_{6}+0.948 X_{4} X_{6}
\end{aligned}
$$

where $Y$ is the predicted value of atrazine degradation and $X_{1}$, $X_{2}, X_{3}, X_{4}, X_{5}$ and $X_{6}$ are the levels of temperature, $\mathrm{pH}$, inoculum size, sucrose, $\mathrm{Na}_{2} \mathrm{HPO}_{4} \cdot 12 \mathrm{H}_{2} \mathrm{O}$ and atrazine concentration, respectively.

\subsection{Effects of interactive factors}

The RSM explained the effects of the different factors in a pronounced way as well as described the interactive effects 
between factors on atrazine degradation. With atrazine degradation as the response, the two dimensional response plots of significant mutual effects (see Table 2) with four factors kept at their central levels and the other two varying within the experimental ranges are shown in Fig. 2.

The interactive effects between temperature and inoculum size, temperature and sucrose, temperature and atrazine concentration (Fig. 2a-c) indicated that the atrazine degradation was highly affected by temperature as compared to the other three factors. Similar contour plots were observed in Fig. 2e-g, where the pair-wise interaction of the twodimensional contours showed significant interactive effects on atrazine degradation between inoculum size and sucrose concentration, inoculum size and $\mathrm{Na}_{2} \mathrm{HPO}_{4} \cdot 12 \mathrm{H}_{2} \mathrm{O}$ concentration, and inoculum size and atrazine concentration.

From Fig. 2a, the increased inoculum size caused a considerable increase in atrazine-degrading efficiency. For instance, an atrazine degradation value of $56.43 \%$ was obtained at $30{ }^{\circ} \mathrm{C}$ and $10 \%(\mathrm{v} / \mathrm{v})$ inoculum size, compared with that of $37.75 \%$ at

Table 2 ANOVA results for the atrazine degradation response ${ }^{a}$

\begin{tabular}{|c|c|c|c|c|c|c|}
\hline Source & Coefficient & DF & SS & MS & $F$-Value & $p$-Value \\
\hline Model & & 28 & 7560.13 & 270.00 & 69.58 & $<0.0001^{b}$ \\
\hline$X_{1}$ & 0.479 & 1 & 7.80 & 7.80 & 2.01 & $0.169^{c}$ \\
\hline$X_{2}$ & 2.811 & 1 & 268.64 & 268.64 & 69.23 & $<0.0001^{b}$ \\
\hline$X_{3}$ & 8.255 & 1 & 2316.77 & 2316.77 & 597.07 & $<0.0001^{b}$ \\
\hline$X_{4}$ & 2.235 & 1 & 169.88 & 169.88 & 43.78 & $<0.0001^{b}$ \\
\hline$X_{5}$ & 0.584 & 1 & 11.58 & 11.58 & 2.98 & $0.096^{c}$ \\
\hline$X_{6}$ & -9.964 & 1 & 3375.25 & 3375.25 & 869.85 & $<0.0001^{b}$ \\
\hline$X_{1}{ }^{2}$ & -3.21 & 1 & 31.16 & 31.16 & 6.30 & $0.019^{b}$ \\
\hline$X_{2}{ }^{2}$ & 1.58 & 1 & 51.88 & 51.88 & 1.52 & $0.229^{c}$ \\
\hline$X_{3}{ }^{2}$ & 2.53 & 1 & 32.25 & 32.25 & 3.92 & $0.059^{c}$ \\
\hline$X_{4}^{2}$ & -2.53 & 1 & 4.45 & 4.45 & 3.92 & $0.059^{c}$ \\
\hline$X_{5}^{2}$ & 1.34 & 1 & 10.66 & 10.66 & 1.10 & $0.304^{c}$ \\
\hline$X_{6}^{2}$ & 3.94 & 1 & 36.89 & 36.89 & 9.51 & $0.005^{b}$ \\
\hline$X_{1} \times X_{2}$ & 0.320 & 1 & 3.28 & 3.28 & 0.84 & $0.367^{c}$ \\
\hline$X_{1} \times X_{3}$ & -1.020 & 1 & 33.29 & 33.29 & 8.58 & $0.007^{b}$ \\
\hline$X_{1} \times X_{4}$ & -1.427 & 1 & 65.15 & 65.15 & 16.79 & $<0.0001^{b}$ \\
\hline$X_{1} \times X_{5}$ & -0.384 & 1 & 4.73 & 4.73 & 1.22 & $0.280^{c}$ \\
\hline$X_{1} \times X_{6}$ & 1.137 & 1 & 41.36 & 41.36 & 10.66 & $0.003^{b}$ \\
\hline$X_{2} \times X_{3}$ & 0.114 & 1 & 0.42 & 0.42 & 0.11 & $0.745^{c}$ \\
\hline$X_{2} \times X_{4}$ & 0.502 & 1 & 8.08 & 8.08 & 2.08 & $0.161^{c}$ \\
\hline$X_{2} \times X_{5}$ & -1.307 & 1 & 54.71 & 54.71 & 14.10 & $0.001^{b}$ \\
\hline$X_{2} \times X_{6}$ & 0.425 & 1 & 5.78 & 5.78 & 1.49 & $0.234^{c}$ \\
\hline$X_{3} \times X_{4}$ & -0.781 & 1 & 19.53 & 19.53 & 5.03 & $0.034^{b}$ \\
\hline$X_{3} \times X_{5}$ & -0.829 & 1 & 21.98 & 21.98 & 5.66 & $0.025^{b}$ \\
\hline$X_{3} \times X_{6}$ & 4.923 & 1 & 775.39 & 775.39 & 199.83 & $<0.0001^{b}$ \\
\hline$X_{4} \times X_{5}$ & 0.248 & 1 & 1.97 & 1.97 & 0.51 & $0.483^{c}$ \\
\hline$X_{4} \times X_{6}$ & 0.948 & 1 & 28.77 & 28.77 & 7.41 & $0.012^{b}$ \\
\hline$X_{5} \times X_{6}$ & -0.707 & 1 & 15.99 & 15.99 & 4.12 & $0.053^{c}$ \\
\hline $\begin{array}{l}\text { Residual } \\
\text { error }\end{array}$ & & 25 & 97.01 & 3.88 & & \\
\hline Lack of fit & & 17 & 78.52 & 4.62 & 2.00 & $0.161^{c}$ \\
\hline Pure error & & 8 & 18.49 & 2.31 & & \\
\hline Total error & & 53 & 7657.14 & & & \\
\hline
\end{tabular}

${ }^{a}$ Note: $R^{2}=0.9873$; coefficient of variation $(\mathrm{CV})=1.97$; adj. $R^{2}=0.9731$. $\mathrm{DF}=$ degrees of freedom; $\mathrm{SS}=$ sum of squares; $\mathrm{MS}=$ mean square. $X_{1}=$ temperature; $X_{2}=\mathrm{pH} ; X_{3}=$ inoculum size; $X_{4}=$ sucrose; $X_{5}=$ $\mathrm{Na}_{2} \mathrm{HPO}_{4} \cdot 12 \mathrm{H}_{2} \mathrm{O} ; X_{6}=$ atrazine concentration. ${ }^{b}$ Significant at " $p$ value" less than 0.05 . ${ }^{c}$ Insignificant at " $p$-value" more than 0.05 .
$30{ }^{\circ} \mathrm{C}$ and $5 \%(\mathrm{v} / \mathrm{v})$. Within the range tested, inoculum size could play a stimulative role in the consideration of atrazine degradation by ZXY-2. However, Mohana et al. ${ }^{24}$ reported that pollutant removal rate increased with inoculum size to its low condition. Hence, different inoculum size levels result in different degradation efficiency.

The elliptical contour plot in Fig. 2b indicates that the atrazine degradation rate increased with rising temperature and sucrose concentration to an optimal point, and then decreased with further increase in temperature and sucrose concentration. The maximum atrazine removal was observed in the range of temperature from 32.02 to $37.68{ }^{\circ} \mathrm{C}$ while sucrose concentration from $1.82 \mathrm{~g} \mathrm{~L}^{-1}$ to $3 \mathrm{~g} \mathrm{~L}^{-1}$. In Fig. $2 \mathrm{~d}, \mathrm{Na}_{2} \mathrm{HPO}_{4} \cdot 12 \mathrm{H}_{2} \mathrm{O}$ concentration reached a plateau level response above the midrange in its interaction with $\mathrm{pH}$, indicating that the $\mathrm{Na}_{2} \mathrm{HPO}_{4}$ $\cdot 12 \mathrm{H}_{2} \mathrm{O}$ concentration had already reached an asymptotic value for atrazine degradation.

Fig. $2 \mathrm{~g}$ showed that atrazine degradation rates were similar at all ranges of inoculum size at low atrazine concentration. However, the degradation rate increased with increasing inoculum size when the atrazine concentration was high, indicating that high inoculum size might have positive effects on atrazine removal. Furthermore, it must be highlighted that atrazine degradation changed from $31.98 \%$ at $100 \mathrm{mg} \mathrm{\textrm {L } ^ { - 1 }}$ atrazine concentration to $61.35 \%$ at $50 \mathrm{mg} \mathrm{L}{ }^{-1}$ atrazine concentration when inoculum size was $5 \%(\mathrm{v} / \mathrm{v})$. Higher atrazine concentrations led to longer lag phases on the microbial biodegradation. ${ }^{25}$ Therefore, higher atrazine concentration resulted in lower atrazine degradation at the fixed time of $3 \mathrm{~h}$.

The interactive effects of atrazine concentration with temperature and sucrose concentration had a positive effect on the degradation of atrazine as shown in Fig. $2 \mathrm{c}$ and h. The contour plots show that at any given atrazine concentration the atrazine removal efficiency changed only slightly between low and high temperature and sucrose concentrations. However, the response value changed sharply (from $37.61 \%$ to $62.34 \%$ and $36.72 \%$ to $62.29 \%$, respectively) as the atrazine concentration decreased. This indicated that atrazine concentration had a greater effect on the model output than either temperature or sucrose concentration in the current experimental ranges. Similarly, the atrazine concentration $\left(X_{6}\right)$ coefficient value was 4.5 -fold higher than the sucrose concentration term $\left(X_{4}\right)$ and 20.8-fold higher than the temperature term $\left(X_{1}\right)$ (Table 2). These results support the suggestion that initial atrazine concentration may be one of the most critical factors in the biodegradation process of atrazine. ${ }^{1}$

\subsection{Optimal atrazine removal and validation experiments}

Based on the results of the RSM, the optimal culturing conditions of $34.04{ }^{\circ} \mathrm{C}, \mathrm{pH} 9.0,10 \%(\mathrm{v} / \mathrm{v})$ inoculum size, $2.212 \mathrm{~g} \mathrm{~L}^{-1}$ sucrose, $6 \mathrm{~g} \mathrm{~L}^{-1} \mathrm{Na}_{2} \mathrm{HPO}_{4} \cdot 12 \mathrm{H}_{2} \mathrm{O}$, and $50 \mathrm{mg} \mathrm{L}{ }^{-1}$ atrazine predicted a maximum atrazine degradation of $74.65 \%$ after $3 \mathrm{~h}$ cultivation $\left(12.73 \mathrm{mg} \mathrm{L}^{-1} \mathrm{~h}^{-1}\right.$ ). Three replicate runs at optimal conditions were carried out to verify the accuracy of the quadratic model. Under optimal conditions, the observed removal value was $76.36 \%$ within 3 hours. This coincided with the predicted value, and the model was validated. 

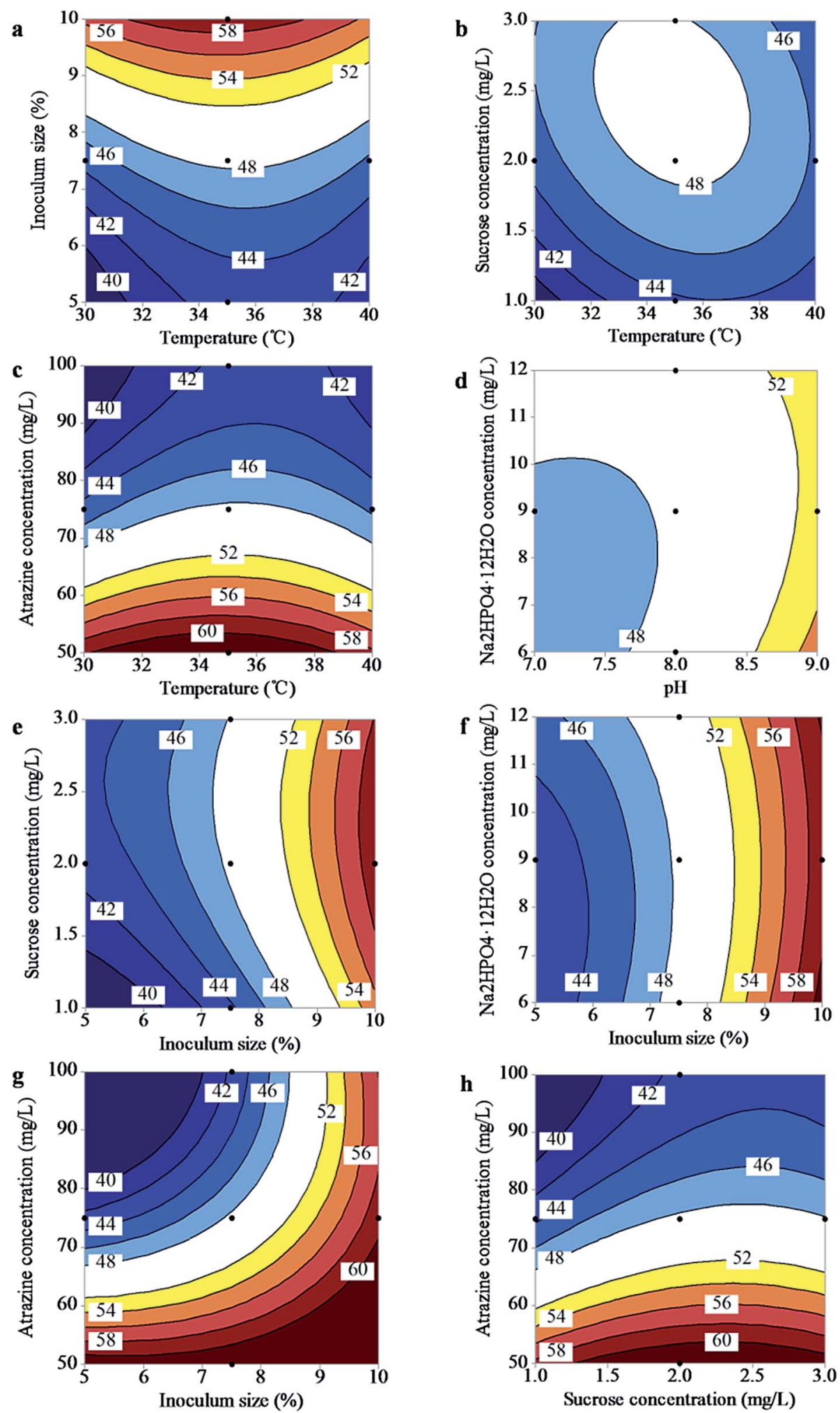

Fig. 2 Two-dimensional significant contour plots for atrazine degradation efficiencies (\%): effect of (a) temperature and inoculum size; (b) temperature and sucrose concentration; (c) temperature and atrazine concentration; (d) $\mathrm{pH}$ and $\mathrm{Na}_{2} \mathrm{HPO}_{4} \cdot 12 \mathrm{H}_{2} \mathrm{O}$ concentration; (e) inoculum size and sucrose concentration; (f) inoculum size and $\mathrm{Na}_{2} \mathrm{HPO}_{4} \cdot 12 \mathrm{H}_{2} \mathrm{O}$ concentration; (g) inoculum size and atrazine concentration; and (h) sucrose concentration and atrazine concentration. 


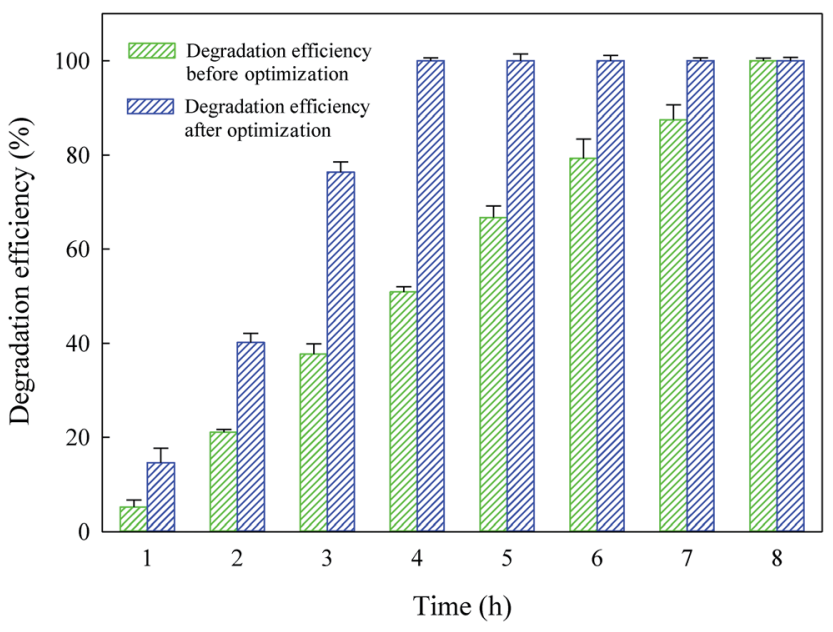

Fig. 3 The atrazine degradation efficiency by strain ZXY-2 before and after optimization.

\subsection{Evaluation of the modified culturing conditions}

This study introduced modified culturing conditions to significantly enhance the biodegradation efficiency of atrazine under optimal conditions. Compared to MSM and other commonly used media with at least ten components, the optimized culture medium could generate a higher atrazine-degrading efficiency of $12.73 \mathrm{mg} \mathrm{L}^{-1} \mathrm{~h}^{-1}$ with only two components (sucrose and $\left.\mathrm{Na}_{2} \mathrm{HPO}_{4} \cdot 12 \mathrm{H}_{2} \mathrm{O}\right)$. $^{4,15,26,27}$ Additionally, the optimal conditions established in this study permitted a high cell density of $2 \times 10^{8}$ $\mathrm{CFU} \mathrm{mL} \mathrm{m}^{-1}$ to be reached within $3 \mathrm{~h}$, a 28.6-fold increase as compared to that of the basal culturing conditions (see Section 2.1 Isolation and enrichment). To our knowledge, the cell density of $2 \times 10^{8} \mathrm{CFU} \mathrm{mL} \mathrm{mL}^{-1}$ is the highest reported to date among the atrazine-degrading strains. ${ }^{\mathbf{8 , 1 4}}$

The degradation performance by strain ZXY-2 was compared before and after optimization of conditions (Fig. 3). In the optimized medium, the degradation efficiency reached $100 \%$ within $4 \mathrm{~h}$, while it was $50.9 \%$ in the original mineral salts medium. Results revealed that strain ZXY-2 had an increased ability to biodegrade atrazine in a shorter period of time under the optimal conditions. As a consequence, the modified culture conditions will greatly improve atrazine biodegradation by strain ZXY-2.

\section{Conclusions}

This study isolated and identified a new atrazine-degrading Arthrobacter sp. ZXY-2 with high atrazine removal efficiency and high salinity tolerance. PB design and RSM were used to determine the significant factors influencing atrazine degradation in order to achieve maximum atrazine degradation. The most favorable conditions for biodegradation were $34.04{ }^{\circ} \mathrm{C}, \mathrm{pH}$ 9.0, inoculum size of $10 \%(\mathrm{v} / \mathrm{v}), 2.212 \mathrm{~g} \mathrm{~L}^{-1}$ sucrose, $6 \mathrm{~g} \mathrm{~L}^{-1}$ $\mathrm{Na}_{2} \mathrm{HPO}_{4} \cdot 12 \mathrm{H}_{2} \mathrm{O}$, and $50 \mathrm{mg} \mathrm{L}^{-1}$ atrazine, providing a maximum atrazine degradation efficiency of $12.73 \mathrm{mg} \mathrm{L}^{-1}$ $\mathrm{h}^{-1}$. The optimal conditions were further validated and showed significant improvement in atrazine degradation. A more thorough investigation will focus on the genomics and transcriptomics in order to understand the highly-efficient and salttolerant mechanisms of ZXY-2. We propose that the present study be used as an application framework for atrazine bioremediation.

\section{Conflict of interest}

None declared.

\section{Acknowledgements}

This work was supported by the Major Science and Technology Program for Water Pollution Control and Treatment (2012ZX07201003).

\section{References}

1 E. Silva, A. M. Fialho, I. Sa-Correia, R. G. Burns and L. J. Shaw, Environ. Sci. Technol., 2004, 38, 632-637.

2 Fazlurrahman, M. Batra, J. Pandey, C. R. Suri and R. K. Jain, Lett. Appl. Microbiol., 2009, 49, 721-729.

3 F. Govantes, O. Porrua, V. Garcia-Gonzalez and E. Santero, Microb. Biotechnol., 2009, 2, 178-185.

4 J. Wang, L. Zhu, Q. Wang, J. Wang and H. Xie, PLoS One, 2014, 9, e107270.

5 M. S. B. M. L. Wackett, Appl. Microbiol. Biotechnol., 2002, 58, 39-45.

6 M. A. Shir, M. Dehghani and M. R. Samaei, J. Health Sci. Surveillance Sys., 2016, 4, 121-128.

7 P. Singh, C. R. Suri and S. S. Cameotra, Biochem. Biophys. Res. Commun., 2004, 317, 697-702.

8 T. El Sebaï, M. Devers-Lamrani, F. Changey, N. Rouard and F. Martin-Laurent, Int. Biodeterior. Biodegrad., 2011, 65, 1249-1255.

9 R. T. Mandelbaum, D. L. Allan and L. P. Wackett, Appl. Environ. Microbiol., 1995, 61, 1451-1457.

10 X. Zhao, L. Wang, F. Ma, S. Bai, J. Yang and S. Qi, J. Environ. Sci., 2017, 54, 152-159.

11 N. Shapir, R. T. Mandelbaum and H. Gottlieb, J. Ind. Microbiol. Biotechnol., 1998, 20, 153-159.

12 S. Xie, R. Wan, Z. Wang and Q. Wang, Environ. Sci. Pollut. Res., 2013, 20, 4078-4084.

13 Q. Wang and S. Xie, Int. Biodeterior. Biodegrad., 2012, 71, 6165.

14 X. Zhou, Q. Wang, Z. Wang and S. Xie, Environ. Sci. Pollut. Res., 2013, 20, 2484-2491.

15 J. Wang, L. Zhu, A. Liu, T. Ma, Q. Wang, H. Xie, J. Wang, T. Jiang and R. Zhao, Environ. Geochem. Health, 2011, 33, 259-266.

16 L. Du, Y. Yang, G. Li, S. Wang, X. Jia and Y. Zhao, Int. Biodeterior. Biodegrad., 2010, 64, 566-573.

17 Y. Kong, P. Zou, L. Miao, J. Qi, L. Song, L. Zhu and X. Xu, Environ. Sci. Pollut. Res., 2014, 21, 5983-5990.

18 Y. Xiao, S. Chen, Y. Gao, W. Hu, M. Hu and G. Zhong, Appl. Microbiol. Biotechnol., 2015, 99, 2849-2859. 
19 I. Amalraj Appavoo, J. Hu, Y. Huang, S. F. Li and S. L. Ong, Water Res., 2014, 57, 270-279.

20 C. A. Velis, C. Franco-Salinas, C. O'Sullivan, J. Najorka, A. R. Boccaccini and C. R. Cheeseman, Environ. Sci. Technol., 2014, 48, 7527-7535.

21 C. Zhang, L. Jia, S. Wang, J. Qu, K. Li, L. Xu, Y. Shi and Y. Yan, Bioresour. Technol., 2010, 101, 3423-3429.

22 Y. Yus Azila, M. D. Mashitah and S. Bhatia, Bioresour. Technol., 2008, 99, 8549-8552.
23 S. I. Mulla, H. Wang, Q. Sun, A. Hu and C. P. Yu, Sci. Rep., 2016, 6, 21965.

24 S. Mohana, S. Shrivastava, J. Divecha and D. Madamwar, Bioresour. Technol., 2008, 99, 562-569.

25 X. Peng and X. Jia, Bioresour. Technol., 2013, 148, 386-393.

26 Y. Zhang, Z. Jiang, B. Cao, M. Hu, Z. Wang and X. Dong, Int. Biodeterior. Biodegrad., 2011, 65, 1140-1144.

27 Q. Li, Y. Li, X. Zhu and B. Cai, J. Environ. Sci., 2008, 20, 12261230. 